\title{
Harmonic Investigation of Compact Fluorescent Lamps Low Energy Consumption Lamps of Cameroonian Market
}

\section{S. Perabi Ngoffe ${ }^{1 *}$, S. Ndjakomo Essiane ${ }^{1}$, Florence Offole ${ }^{2}$, Ghislain Mengata Mengounou ${ }^{1}$, Adolphe Moukengue Imano', Onambele ${ }^{1}$}

${ }^{1}$ Laboratory of Technology and Applied Sciences, University of Douala, Douala, Cameroun

${ }^{2}$ Engineering Sciences Laboratory, University of Douala, Douala, Cameroun

Email: *ngoffeperabi@yahoo.fr

How to cite this paper: Perabi Ngoffe, S., Ndjakomo Essiane, S., Offole, F., Mengata Mengounou, G., Moukengue Imano, A. and Onambele (2019) Harmonic Investigation of Compact Fluorescent Lamps Low Energy Consumption Lamps of Cameroonian Market. Open Access Library Journal, 6: e5446.

https://doi.org/10.4236/oalib.1105446

Received: May 6, 2019

Accepted: May 24, 2019

Published: May 27, 2019

Copyright $\odot 2019$ by author(s) and Open Access Library Inc.

This work is licensed under the Creative Commons Attribution International License (CC BY 4.0).

http://creativecommons.org/licenses/by/4.0/

\begin{abstract}
This article presents a study of compact fluorescent lamps (CFLs) low energy consumption lamps found in the Cameroonian market. The current obtained in the experimental setup has been analyzed in Matlab Simulink. The results obtained show that the THD of different lamps does not respect the standard IEC-61000-3-2. These values increase with the power of lamps. Spectral analysis of these lamps shows that the probable cause of their premature degradation results from the effects of harmonics on the capacitors. This degradation is all more precocious as the rank and the concerned $T H D_{i}$ is great. That's why $75 \mathrm{~W}$ lamps are more sensitive than others.
\end{abstract}

\section{Subject Areas \\ Electric Engineering}

Keywords

Harmonic, Pollution, Compact Fluorescent Lamp, THD, Spectrum Harmonic

\section{Introduction}

Deficit electric energy in the world and mainly in Africa has led states to adopt energy efficiency policies. These policies concern production and consumption fields. Consumption of electrical energy by electric lighting is estimated at $20 \%$ world consumption. To reduce this, Cameroonians have chosen low-energy lamps. Among these, we find mainly LED lamps and compact fluorescent lamps (CFLs) with electronic ballast. The lifespan ranging of CFL is estimated between $6000 \mathrm{~h}$ and 15,000 $\mathrm{h}$ but in pratic we observe a premature deterioration of these. 
Analysis of power supplies of these faulty lamps shows that they are RCD (resistor, capacitor and diodes) types [1] and the most critical element is capacitor. These failures can have several causes; harmonic pollution is one of them. Harmonic currents originate from the absorption of non-sinusoidal currents by non-linear loads [2]. CFLs by their alimentation structures are nonlinear load [3]. Effects of harmonics are numerous, ranging from abnormal heating of conductors to the destruction of electric components [4] [5] [6]. These effects concern the components connected to the same node of an electrical network and vary according to the harmonic rank and their rate in the signal. The electromagnetic compatibility standards limit this harmonic pollution depending on type and power of load [7] [8] [9]. Several solutions exist to this phenomenon, among them: sizing, compensation, and filtering [10]. Knowledge of harmonic spectrum makes it possible not only to diagnose failures causes of electric components, but also to design adapted filters. The article aim is to investigate the harmonic pollution of CFLs. It is subdivided into three parts. The first is a review of the literature on harmonics and analysis methods, the second presents the methods and tools used to carry out our investigation and the last is a presentation of results.

\section{Related Work}

Harmonics are the sinusoidal voltages or currents whose frequency is an integer multiple of frequency network (50 hz in Cameroon) called fundamental. A signal polluted is a superposition of this different harmonics that can modeled by following equation:

$$
f(t)=a_{0}+\sum_{n=1}^{\infty}\left(a_{n} \cos (n w t)+b_{n} \sin (n w t)\right)
$$

where $n$ is harmonic rank and $w=\frac{2 \Pi}{T}$ the electric pulse

$a_{0}, a_{n}, b_{n}$, are real constants with:

$a_{0}$ the average value of the electrical signal given by:

$$
a_{0}=\frac{1}{T} \int^{T} f(t) \mathrm{d} t
$$

$a_{n}$ the real part of signal amplitude

$$
a_{n}=\frac{2}{T} \int^{T} f(t) \cos (n \omega t) \mathrm{d} t
$$

$b_{n}$ the imaginary part of signal amplitude

$$
b_{n}=\frac{2}{T} \int^{T} f(t) \sin (n \omega t) \mathrm{d} t
$$

For $n=1$ we have the fundamental.

\subsection{Harmonics Sources}

Main harmonics perturbations causes are nonlinear charges. They are generated 
by equipment (electronics components) who supply by DC current. computers, variable speed drives and CFLs are examples. This load type is characterized by generation of deformed current which remains periodic and created sequences zero harmonics like: rank 7 and 13 witch are sequence positive; rank 5 and 11 witch are sequence negative; rank 3 and 9 witch are sequence zero [11].

\subsection{Harmonic Currents Characteristics}

Electric characteristics of a periodic signal deformed are:

- The total rms value

If $I_{k}$ is rms value of harmonic current at rank $k$, the total $r m s$ value is given by Equation (2)

$$
I_{r m s}=\sqrt{\sum_{k=1}^{n} I_{k}^{2}}
$$

- The individual harmonic distortion rate

It gives relation between rms value of harmonic and the fundamental

$$
T H D_{i} \%=\frac{I_{K}}{I_{1}} \times 100
$$

- Total harmonic distortion

It characterizes signal distortion rate, their expression is given by Equation (4)

$$
T H D \%=\frac{\sqrt{\sum_{k=2}^{n} I_{k}^{2}}}{I_{1}} \times 100
$$

- The harmonic spectrum

It consists of determining magnitude or THDI (voltage or current) at different signal harmonics rank. the spectral density gives similar information. Figure 1 shows an example of a spectrum.

- The power factor

It is ratio between active power $(P)$ and apparent power $(S)$. It does not translate difference phase between voltage and current of load. Equation (5) give their expression:

$$
\lambda=\frac{P}{S}
$$

- The distortion factor

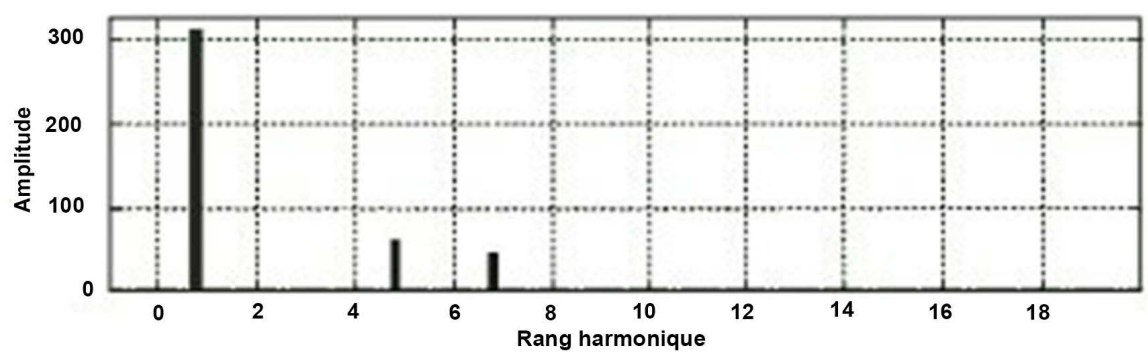

Figure 1. Harmonic spectrum. 
It is ratio between power factor and difference phase between current and voltage. It characterizes deformation of the phase shift. If it equal to one, it means that signal has not harmonics. It is given by Equation (6)

$$
v=\frac{\lambda}{\cos \varphi_{1}}
$$

With $\varphi_{1}$ phase shift between voltage and current at the fundamental

- The distortion power

The presence of Harmonics in signal create a power distortion given by following relation [12]:

$$
D^{2}=S^{2}-P_{1}^{2}-Q_{1}^{2}
$$

where $P_{1}$ and $Q_{1}$ are active and reactive powers at the fundamental.

\subsection{The Effects of Harmonics}

Harmonics have several effects in the electric network equipment's, including [1] [4] [5] [6]:

- The heating of cables by joule effect, translated by following equation:

$$
\text { Perte }=r \sum_{k=1}^{n} I_{k}^{2}
$$

With $r$ the cable resistance.

This heating also concerns the protective conductor if spectrum is rich in rank 3 harmonic.

- Destruction of capacitors

Capacitor current is given by following relation:

$$
I=2 \Pi k f C U
$$

where $k$ is the harmonic rank and $f$ the fundamental frequency.

This current increases with the harmonic rank. If capacitor is connected parallel with a transformer or an inductor it can enter resonance at the corresponding eletric pulsation given by Equation (9)

$$
w_{k}^{2}=\frac{1}{L C}
$$

With $w_{k}=2 \Pi k f$

Apart from these consequences we can cite: the nuisance tripping of circuit breakers, sources disturbance, sensitive electronic equipment and others.

\subsection{Standards and Harmonics}

To limit harmonic pollution several standards and directives on electromagnetic compatibility are imposed. These are presented in Table 1 .

Like any device electric, CFLs lamps must comply with IEC 61000-3-2 standard, which states that harmonics emission limits for lamps are subdivided according to their active power (Table 2) [7]. 
Table 1. Standards for harmonic emission limits [7] [8] [9].

\begin{tabular}{cl}
\hline \multicolumn{1}{c}{ Standards } & \multicolumn{1}{c}{ Description } \\
\hline IEC-61000-2-2 & $\begin{array}{l}\text { Compatibility Levels for Low Frequency Conducted Disturbances and } \\
\text { Signal Transmission in Low Voltage Distribution Networks }\end{array}$ \\
IEC-61000-2-4 & $\begin{array}{l}\text { Compatibility levels for low-frequency disturbances in industrial } \\
\text { installations }\end{array}$ \\
IEC-61000-3-2 & $\begin{array}{l}\text { Limitation of harmonic current emissions (equipment with input current } \\
\text { less than 16 A per phase) }\end{array}$ \\
IEC-61000-3-4 & $\begin{array}{l}\text { Limits for harmonic current emissions on low-voltage networks for } \\
\text { equipment with a rated current greater than 16 A. }\end{array}$ \\
IEC-61000-3-12 & $\begin{array}{l}\text { Limits for harmonic currents produced by equipment connected to public } \\
\text { lown } \\
\text { equal to 75 A }\end{array}$ \\
\hline
\end{tabular}

Table 2. Maximum harmonic current allowed.

\begin{tabular}{cccc}
\hline & \multicolumn{2}{c}{ Power less than 25 W. one of these 2 limits applies } & Power greater than $25 \mathrm{~W}$ \\
\cline { 2 - 4 } Table Head & $\begin{array}{c}\text { \% of the fundamental } \\
\text { current }\end{array}$ & $\begin{array}{c}\text { Harmonic current in } \\
\text { relation to the active } \\
\text { power }\end{array}$ & $\begin{array}{c}\text { \% of the fundamental } \\
\text { current }\end{array}$ \\
\hline 3 & 86 & $3.4 \mathrm{ma} / \mathrm{W}$ & 30 \\
5 & 61 & $1.9 \mathrm{ma} / \mathrm{W}$ & 10 \\
\hline
\end{tabular}

\section{Methodology}

Investigation we carried out focused on 3 lamps whose characteristics are given in Table 3.

\subsection{Presentation Experimental Setup}

Measurement of current absorbed by lamps was carried out using the experimental setup shown in Figure 2.

Experimental setup consists of the following elements:

- Connection box to connect lamps and different elements of the bench;

- Switch for switching lamps;

- Computer (output interface) for viewing electrical signal;

- VOLCRAFT digital oscilloscope interface connected to computer;

- A measuring probe; A shunt for currents measurement through voltages image.

\subsection{Treatment and Analysis Platform on Matlab Simulink}

Signal coming from oscilloscope (computer) being noisy, Figure 3 presents Simulink processing and analysis platform.

\section{Results and Discussion}

Voltages at the terminals of our different shunt are presented in Figure 4. 
Table 3. Characteristics of investigated lamps.

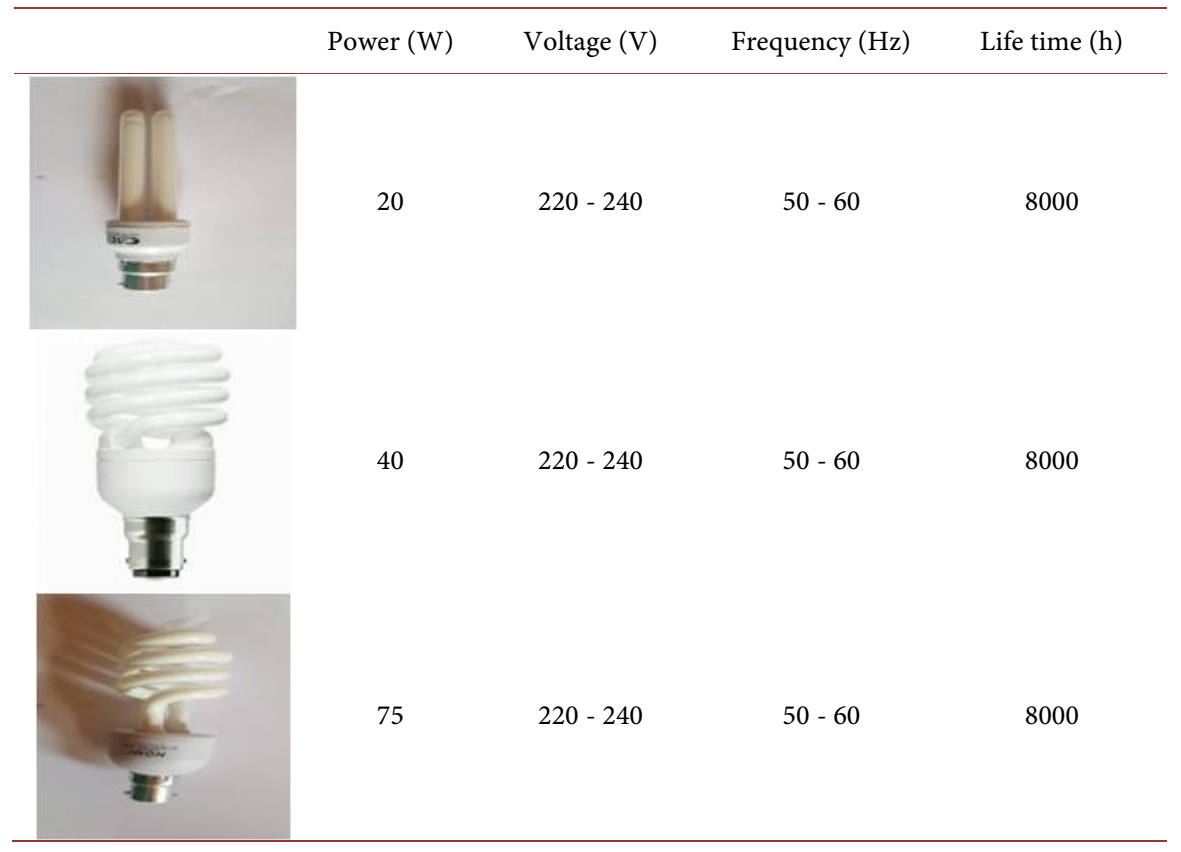

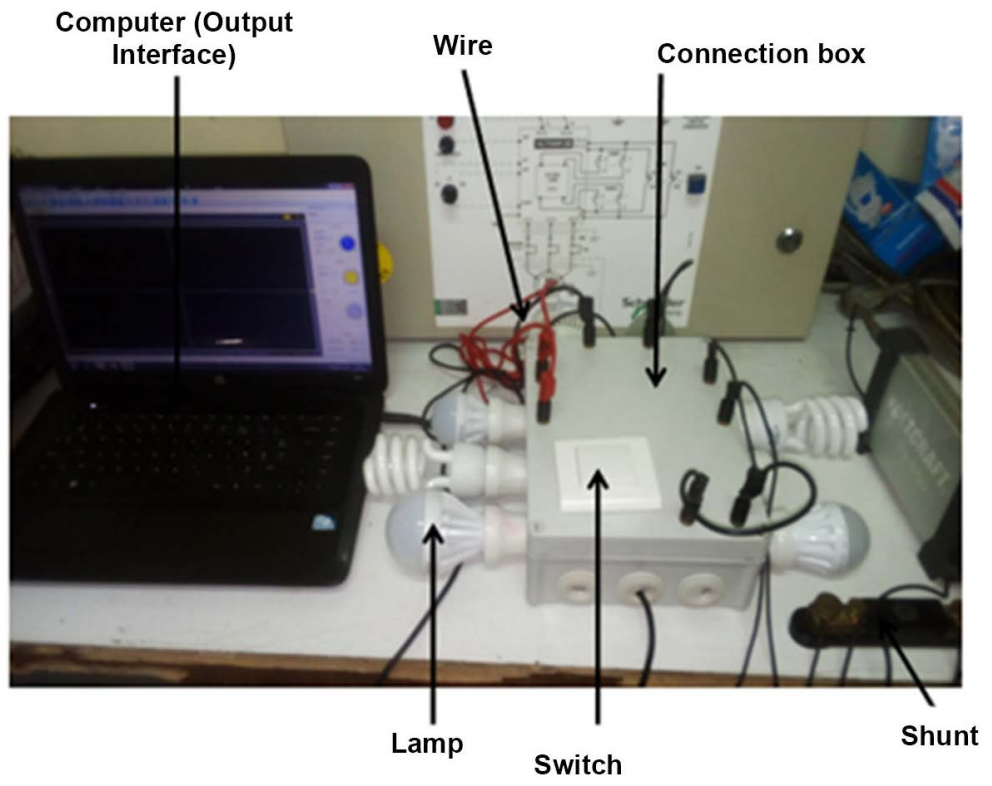

Figure 2. Harmonic spectrum experimental setup.

We note that obtained measurements are quite noisy hence need to filter for better exploitation. After measurement, signal obtained are processing on matlab simulink platform. Results are presented in Figure 5.

Currents obtained are less noisy. Their different THD are presented in Table 4.

It is found that THD increases with the lamps power. values obtained are much higher than the $3 \%$ predicted by standard for class $\mathrm{C}$ equipment. Analysis of spectral density gave the following results in Figure 6. 


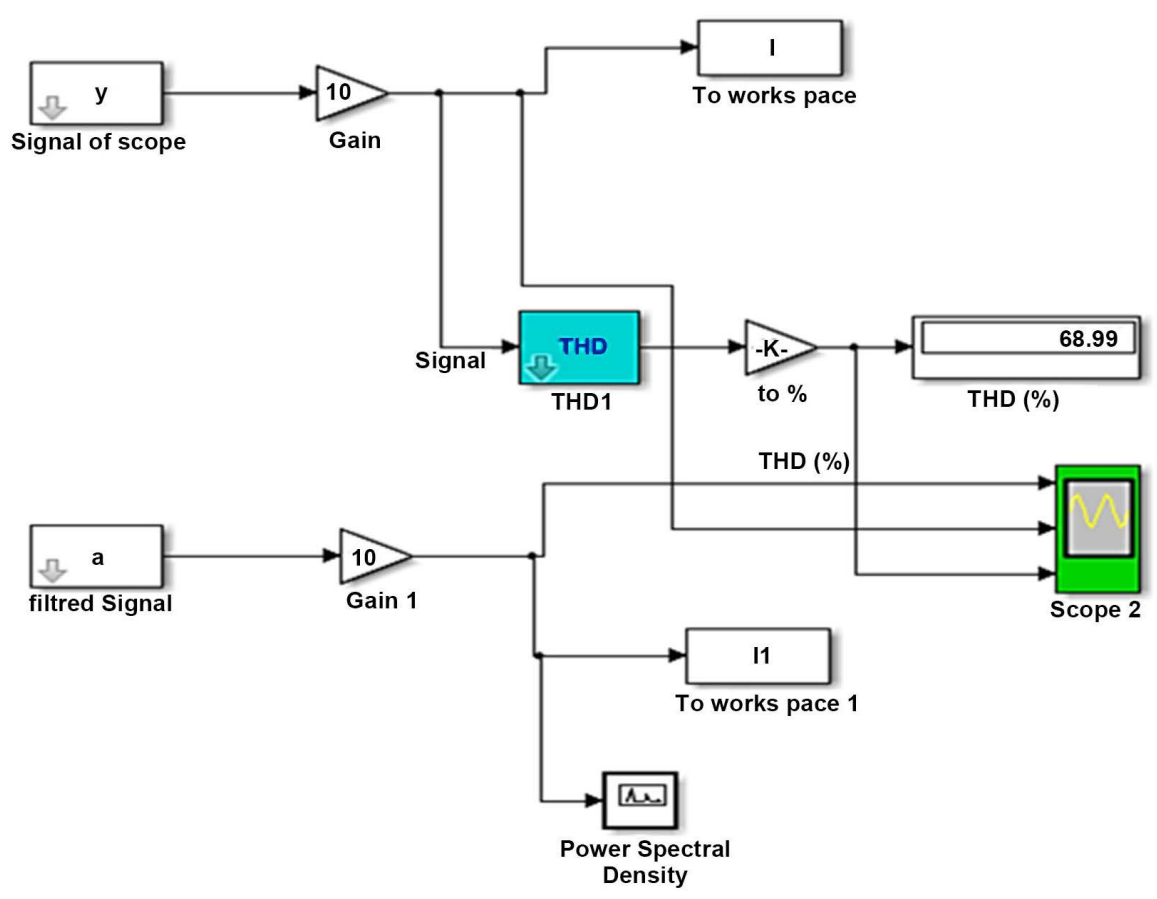

Figure 3. Signal processing and analysis platform.

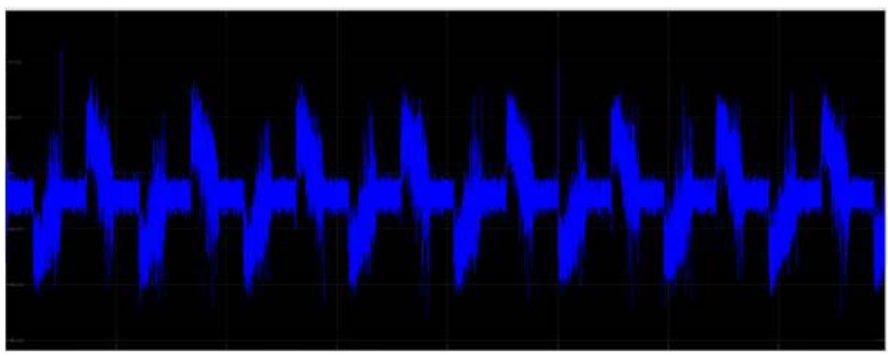

(a)

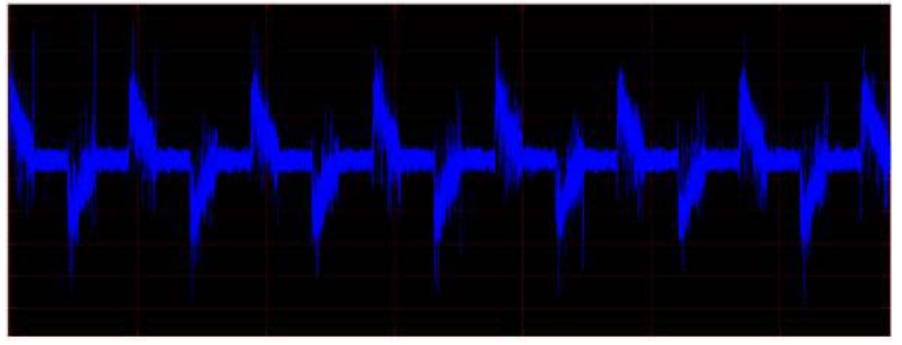

(b)

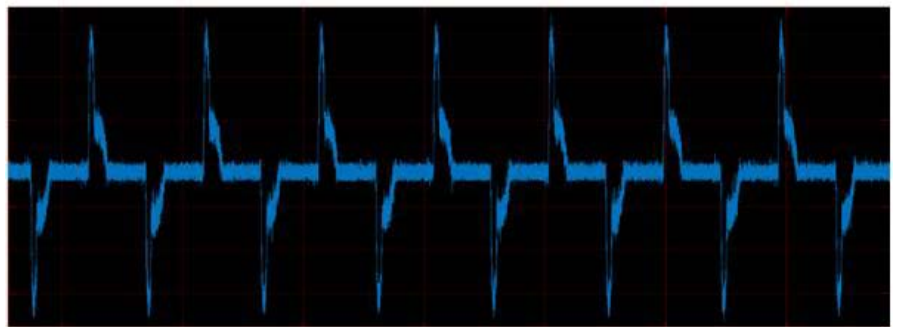

(c)

Figure 4. Shunt voltage. (a) $20 \mathrm{~W}$ lamp; (b) $40 \mathrm{~W}$ lamp; (c) $75 \mathrm{~W}$ lamp. 


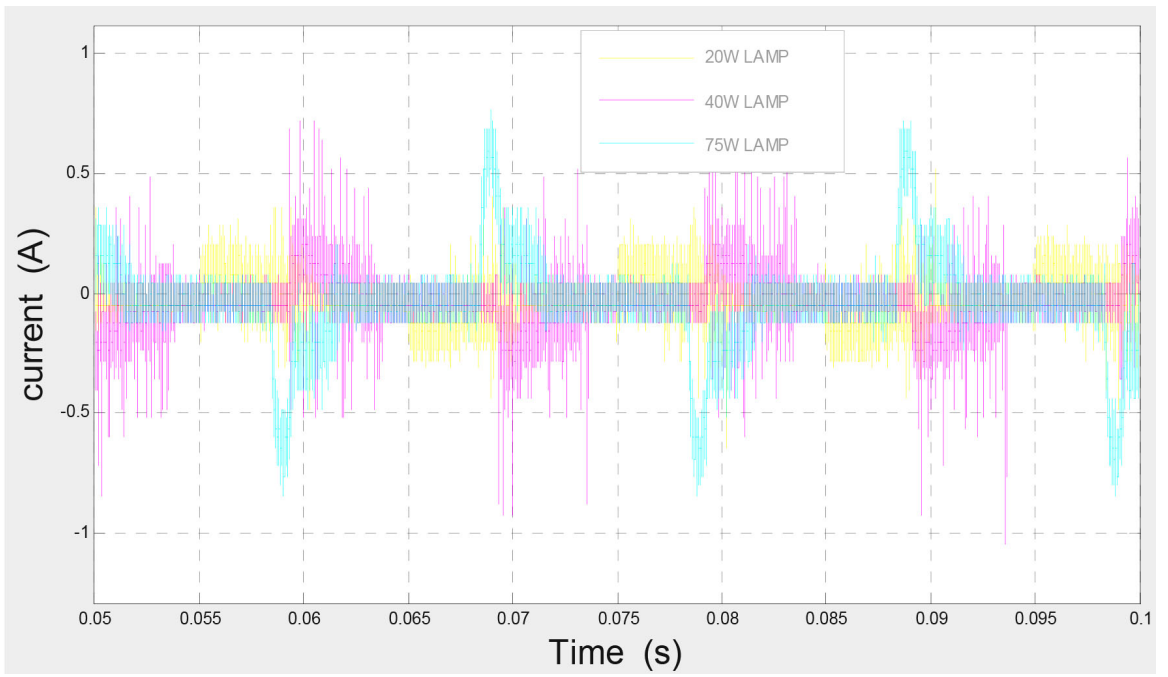

(a)

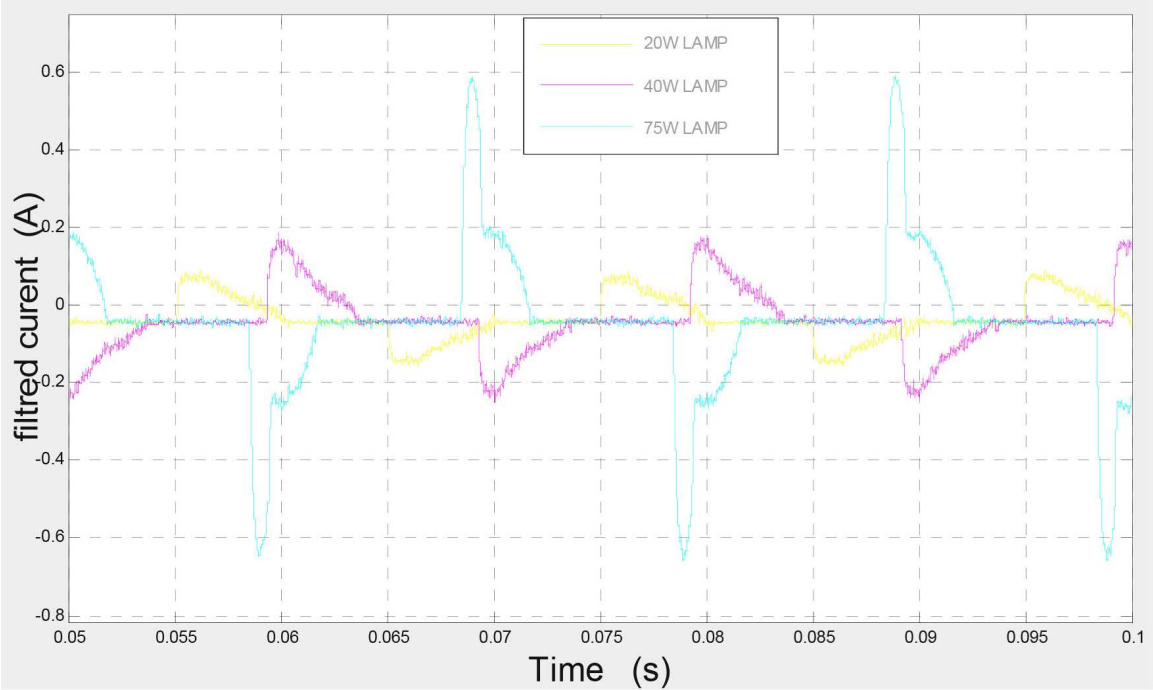

(b)

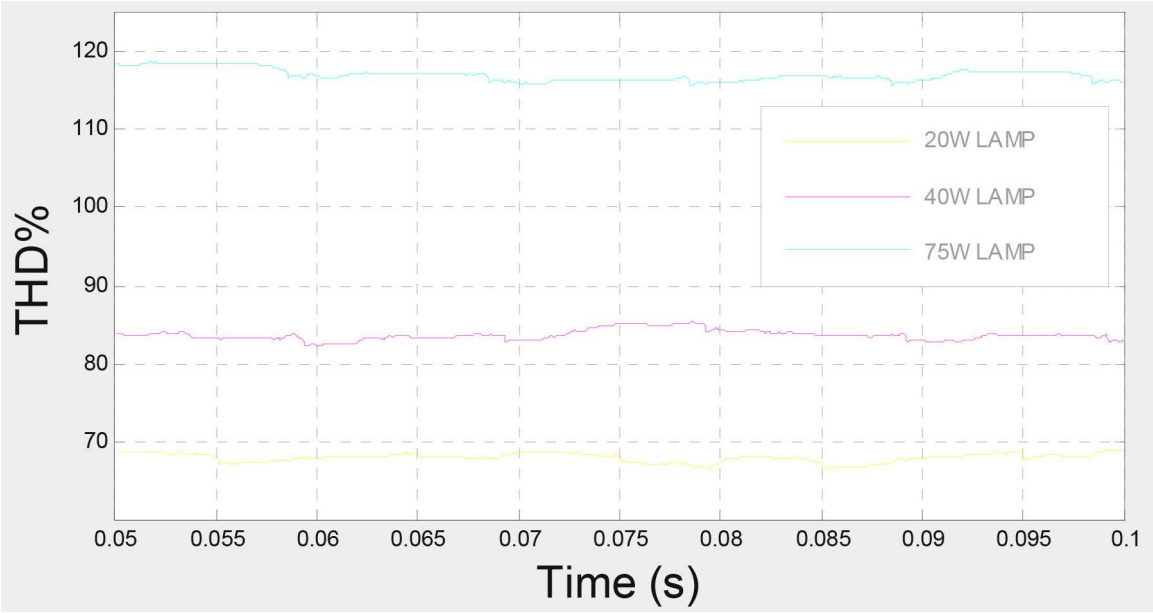

(c)

Figure 5. Simulink platform results. (a) Experimental currents obtained; (b) Filtred currents; (c) THD lamp. 


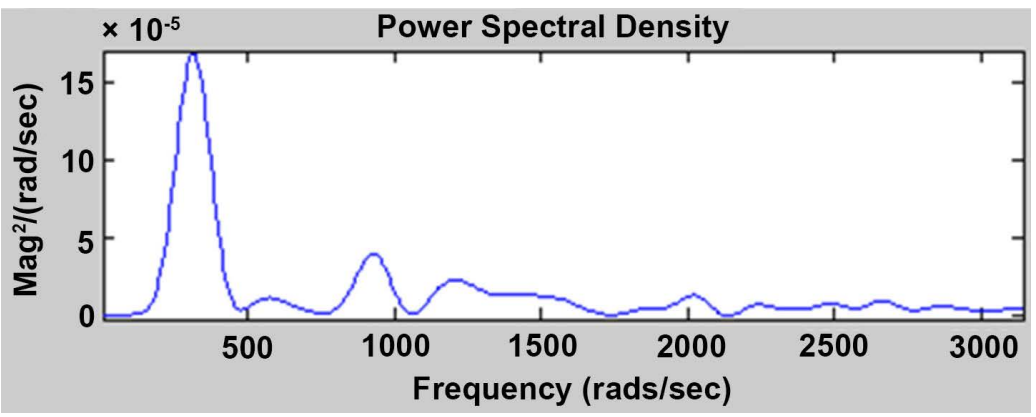

(a)

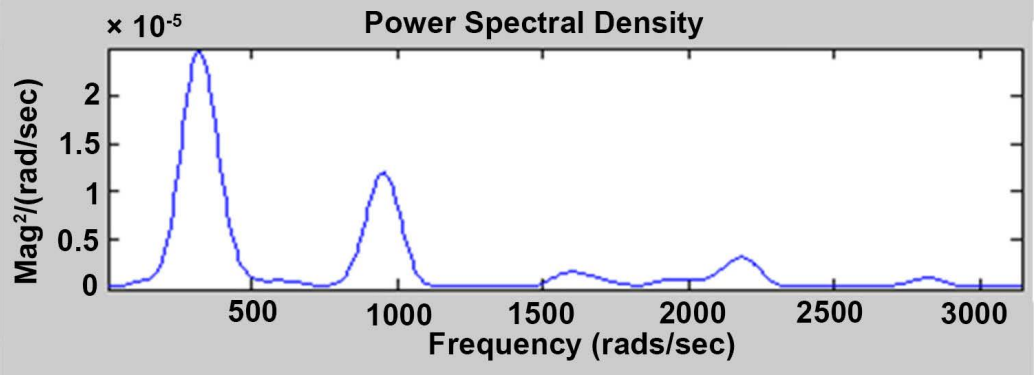

(b)

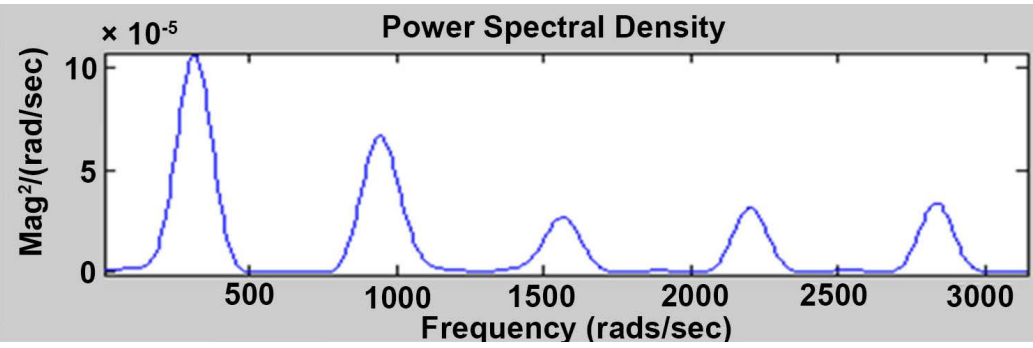

(c)

Figure 6. Spectral density of the currents absorbed by the studied lamps. (a) 20 W lamp; (b) $40 \mathrm{~W}$ lamp; (c) $75 \mathrm{~W}$ lamp.

Table 4. Obtained currents with a THD.

\begin{tabular}{cc}
\hline Lamp & THD (\%) \\
\hline $20 \mathrm{~W}$ & 68.99 \\
$40 \mathrm{~W}$ & 82.94 \\
$75 \mathrm{~W}$ & 116.04
\end{tabular}

Table 5 shows the results of calculation of the $T H D_{i}$ resulting from this spectral density.

We note that at each harmonic rank, $T H D_{i}$ increase with power of lamps. According to the IEC-61000-3-2 standard only the $20 \mathrm{~W}$ lamp is in adequacy with standard (Table 2). In addition, Equations (8) and (9) predict risk of overcurrent in capacitors, and resonance between capacitors, transformer and inductance of the CFLs supply. according to results of Table 5 the $75 \mathrm{~W}$ lamp is most likely to degrade prematurely. 
Table 5. THDi of investigated lamps.

\begin{tabular}{cccc}
\hline \multirow{2}{*}{$\begin{array}{c}\text { Rank of the } \\
\text { harmonic }\end{array}$} & \multicolumn{3}{c}{ THDi lamps (\%) } \\
\cline { 2 - 4 } & $20 \mathrm{~W}$ & $40 \mathrm{~W}$ & $75 \mathrm{~W}$ \\
\hline 1 & 100 & 100 & 100 \\
3 & 37.5 & 58.3 & 64 \\
5 & - & 8.83 & 30 \\
7 & 10 & 16.6 & 37 \\
9 & - & 4.16 & 40 \\
\hline
\end{tabular}

\section{Conclusion}

This article investigates the harmonic pollution of CFLs lamps in order to diagnose the causes of premature degradation of these lamps. For this purpose, experimental setup has been set up to carry out the various tests. Noisy signal obtained was filtered and analyzed in the Matlab Simulink platform. Obtained results show that harmonic spectrum of investigated lamps mainly comprises harmonics of zero sequence. THD obtained increases with power as well as THDi. Comparison of different results with IEC-61000-3-2 IEC standard shows that only the $20 \mathrm{~W}$ lamp is inadequacy at the harmonics 3 and 5. High rate of these THDs suggests that the rapid deterioration cause of these type lamps are effects of harmonics on the capacitors (Equations (8) and (9)).

\section{Acknowledgements}

The authors wish to express their sincere thanks to research team in Electrical Energy System of University of Douala.

\section{Conflicts of Interest}

The authors declare no conflicts of interest regarding the publication of this paper.

\section{References}

[1] Schneider Electric (2015) Elimination des harmoniques dans les installations. Edition $09 / 2015,1-21$

[2] Nohra, M.A.H. (2017) Commande de Filtres Actifs Parallèles sur un Réseau Fortement Perturbé. Ph.D. Thesis, Toulouse University, Toulouse.

[3] Hanna Nohra, A.F., Kanaan, H.Y. and Al-Haddad, K. (2012) A Study on the Impact of a Massive Integration of Compact Fluorescent Lamps on Power Quality in Distribution Power Systems. International Conference on Renewable Energies for Developing Countries (REDEC), Beirut, 28-29 November 2012, 1-6. https://doi.org/10.1109/redec.2012.6416700

[4] Collombet, C., Lupin, J.M. and Schonek, J. (1999) Perturbation harmoniques dans les réseaux polluésetleur traitement. Schneider Electric, cahier technique no. 152.

[5] Abbaspour, M. and Jahanikia, A.H. (2009) Power Quality Consideration in the Widespread Use of Compact Fluorescent Lamps. $10^{\text {th }}$ International Conference on 
Electrical Power Quality and Utilisation, Lodz, 15-17 September 2009, 1-6. https://doi.org/10.1109/epqu.2009.5318824

[6] Richard, M.K. and Sen, P.K. (2010) Compact Fluorescent Lamps and Their Effect on Power Quality and Application Guidelines. IEEE Industry Applications Society Annual Meeting, Houston, 3-7 October 2010, 1-7. https://doi.org/10.1109/ias.2010.5615449

[7] CEI 61000-3-2 Compatibilité électromagnétique (CEM) (2009)-Partie 3-2: Limites-Limites pour lesémissions de courant harmonique (Courant appelé par les appareils 16A par phase) édition 3.2-2009.

[8] CEI 61000-2-2 Compatibilité Electromagnétique (CEM)-Partie 2-2 (2002): Environnement-Niveaux decompatibilité pour les perturbations conduites à basse fréquence et la transmission des signaux surles réseaux publics d'alimentation basse tension. Deuxième édition 2002-03.

[9] IEC 61000-2-4 Compatibilité électromagnétique (CEM)-Partie 2-4 (2002): Environnement-Niveauxde compatibilité dans les installations industrielles pour les perturbations conduites à bassefréquence. Deuxièmeédition 2002-06.

[10] Hanna Nohra, A.F., Kanaan, H.Y. and Fadel, M. (2016) Comparative Evaluation of Harmonic Compensation Methods Based on Power Calculation and Current Harmonic Detection for Single-Phase Applications. IECON 2016-42nd Annual Conference of the IEEE Industrial Electronics Society, Florence, 23-26 October 2016, 3685-3690. https://doi.org/10.1109/iecon.2016.7793331

[11] Schonek, J. (2000) Les singularités de l'harmonique 3. Schneider Electric, cahier technique n 202.

[12] Czarnecki, L.S. (1987) What Is Wrong with the Budeanu Concept of Reactive and distortion power and Why It Should Be Abandoned. IEEE Transactions on Instrumentation and Measurement, IM-36, 834-837.

https://doi.org/10.1109/tim.1987.6312797 